\title{
Immunoadjuvant effect of garlic (Allium sativum)-mineral oil suspension on immunity and resistance to Aeromonas hydrophila infection in rohu, Labeo rohita
}

\author{
Pujarini Dash $\cdot$ Swati Yadav $\cdot$ P. K. Sahoo
}

Received: 6 May 2014/Accepted: 1 July 2014/Published online: 23 July 2014

(C) The Author(s) 2014. This article is published with open access at Springerlink.com

\begin{abstract}
The immunomodulatory effect of garlic-mineral oil as a modified adjuvant was investigated in rohu, Labeo rohita along with formalin-killed Aeromonas hydrophila. The garlic extract was not having any proteolytic effect on the tested antigen as marked in SDS-PAGE. The efficacy of graded levels of modified adjuvant formulation was assessed by measuring serum hemolysin and agglutination titers as well as level of protection against $A$. hydrophila challenge in the immunized fish at days 10 and 30 post-vaccination (dpv). The higher hemolysin and bacterial agglutinin titers along with significantly lower mortality against $A$. hydrophila challenge in modified adjuvant-based vaccinated fish, particularly at low level of garlic incorporation, indicated the pronounced immunoadjuvant role of this modified adjuvant formulation in rohu.
\end{abstract}

Keywords Adjuvant $\cdot$ Allium sativum $\cdot$ Aeromonas hydrophila $\cdot$ Labeo rohita

\section{Introduction}

In fish vaccination, use of adjuvants is a widely practiced method. Selecting an appropriate adjuvant depends on its safety and efficacy profile. Oil-adjuvanted vaccines are greatly in use despite their undesirable side effects as they maintain the persistence and slow release of antigen at the injection site. It is reported that mineral oil causes adverse effects including chronic peritonitis, adhesions, granulomas and in extreme conditions, resulted in decreased growth rate (Midtlyng et al. 1996; Poppe and Breck 1997). On the other hand, Freund's complete adjuvant (FCA) which stimulates the cell-mediated immunity and is known to stimulate tumor necrosis factors also causes unwanted side effects in mammals (Chillingworth and Donaldson 2003). A number of herbal immunostimulants and adjuvants from plant sources are being tried to avoid the chronic reactions produced by different adjuvants. Propolis, a plant product was found to stimulate leukocyte activity and antibody production in carp and increase the survival rate following challenge with $A$. hydrophila (Chu 2006). Similarly, two Chinese herbs namely Astragalus radix and Ganoderma lucidum enhanced immunity in carp against Aeromonas hydrophila infection (Yin et al. 2009). The medicinal effects of garlic (Allium sativum), a commonly used spice, have long been known since time immemorial. It is a proven immunostimulatory as well as anti-infective agent (Reuter et al. 1996). Allium species have immuneenhancing activities viz., promotion of lymphocyte synthesis, release of cytokines, phagocytosis and natural killer cell activity (Kyo et al. 1998). Dietary garlic has been evaluated as an effective immunostimulant in rainbow trout (Nya and Austin 2009) and L. rohita against A. hydrophila infection (Sahu et al. 2007).

P. Dash $\cdot$ S. Yadav $\cdot$ P. K. Sahoo $(\square)$

Central Institute of Freshwater Aquaculture, Kausalyaganga, Bhubaneswar 751002, India

e-mail: pksahoo1@rediffmail.com 
Diseases caused by A. hydrophila are a major problem in aquaculture. This pathogen is associated with various diseases in fish viz., hemorrhagic septicemia, dropsy, epizootic ulcerative syndrome, hemorrhagic enteritis, and red body disease (Angka 1990). A number of fish species including rohu are found to be susceptible to this bacterium (Mu et al. 2011). So far, different types of vaccines are being tried against this pathogen in different fish species with limited success. Using an immunostimulant in combination with an adjuvant in vaccination may be synergistic to strengthen the immunity and protective response of the fish. Garlic has been found to be inhibitory towards bacteria, fungi, viruses and protozoa (Bongiorno et al. 2008). It is reported that the F4 protein of aged garlic extract stimulated the functions of spleen cells and macrophages. Moreover, two agglutinins were found in garlic extract when subjected to aging and were thought to bind to the manan residues of glycoproteins (Chandrasekhar and Venkatesh 2009). Allicin-derived organosulfur compounds and ajoene are principal antibacterial agents present in garlic extract. Besides that, a number of low molecular weight organo-sulfur compounds were found in garlic extract which also possess immunostimulatory activity (Corzo-Martinez et al. 2007). Further, our earlier preliminary findings revealed the reducing peritoneal adhesion effect of mineral oil adjuvant by additional use of garlic with later (data not shown). Hemolytic and agglutinating activities of serum are well correlated with disease resistance of fish (Roed et al. 1992; Marsden et al. 1996). An attempt has been made here to check the efficacy of a modified adjuvant formulation (a mixture of garlic extract and mineral oil, the later being most widely used adjuvant in fish vaccination program), in combination with formalin-killed A. hydrophila cells (FKC) against A. hydrophila infection in rohu, L. rohita. The study evaluates the immunomodulatory effect of the modified adjuvanted vaccine formulation on the above-described immune parameters as well as its potential to protect the fish against $A$. hydrophila infection.

\section{Materials and methods}

Preparation of garlic extract and bacterial antigen

Dry garlic bulbs obtained from local market were peeled, crushed, ground and the extract was prepared by filtering through muslin cloth followed by $0.45 \mu \mathrm{m}$ Whatman's filter paper. Finally, the extract was freeze dried and stored at $4{ }^{\circ} \mathrm{C}$ for further use. One pathogenic isolate of $A$. hydrophila (Ah \#15, a local isolate from ulcer lesions of rohu sampled from the Institute farm) grown on tryptone soy broth for $24 \mathrm{~h}$ at $30^{\circ} \mathrm{C}$, was harvested and washed twice in sterile PBS (sodium chloride $8 \mathrm{~g}$, potassium chloride $0.2 \mathrm{~g}$, disodium hydrogen phosphate dibasic anhydrous $1.15 \mathrm{~g}$, potassium dihydrogen phosphate monobasic anhydrous $0.2 \mathrm{~g}$, distilled water up to $1,000 \mathrm{~mL}$ ). The bacterium was then inactivated with $1 \%$ formalin at $4{ }^{\circ} \mathrm{C}$ for overnight, washed twice in PBS and checked for sterility by streaking on tryptone soy agar.

SDS-PAGE to check the effect of garlic extract on bacterial antigen stability

The bacterium was diluted in PBS to match Mc Farland Standard no. $9\left(2.6 \times 10^{9}\right.$ cells $\left./ \mathrm{mL}\right)$. The freeze-dried garlic extract was made into aliquots in three tubes containing 10, 100 and 1,000 $\mu \mathrm{g}$ of the freeze-dried product to which $100 \mu \mathrm{L}$ of formalin-killed A. hydrophila was added. These samples were incubated at room temperature for 1 and $6 \mathrm{~h}$, respectively, and the incubated samples were subjected to SDS-PAGE (10\%) to check the effect of garlic on formalin-killed bacterial cells, which is commonly being used as a vaccine candidate/immunogen (Salamatdoust and Kiyani 2012).

Fish and experimental setup

Indian major carp, L. rohita (420 numbers) juveniles were obtained from one of the culture ponds of the CIFA farm and acclimatized for 2 weeks before conducting the experiment. The juveniles weighing $\sim 60 \mathrm{~g}$ were stocked in $700 \mathrm{~L}$ ferrocement tanks in wet laboratory and fed with commercial pellet diet (ABIS floating feed, Indian Solvent Industry, India) at $3 \%$ of body weight in two divided doses daily. One-tenth of the water in the tank was exchanged daily. The water temperature in the tanks varied from 28 to $30{ }^{\circ} \mathrm{C}$ during the experiment. The rohu juveniles were randomly divided into seven different experimental groups 
containing 60 fish in each group. Group A served as negative control, group B received only $0.2 \mathrm{~mL}$ of PBS injection, group $\mathrm{C}$ received $0.2 \mathrm{~mL}$ of mineral oil (MO), group $\mathrm{D}$ received $0.2 \mathrm{~mL}$ of formalin-killed $A$. hydrophila (FKC) suspension $\left(10^{8}\right.$ cells/fish) in PBS and mineral oil (1:1), groups E, F and G received 10, $100,1,000 \mu \mathrm{g}$ of freeze-dried garlic powder suspended in $0.2 \mathrm{~mL}$ of mineral oil: FKC suspension in 1:1 ratio (intraperitoneal immunization). Each group was divided into two subgroups according to two experimental time periods, i.e., 10 and 30 days of trials. Further, each subgroup containing thirty fish was randomly distributed into six tanks (500 L ferrocement tank) with five fish in each. Out of those six tanks, fish of three tanks were utilized for studying immune parameters whereas rest three tanks for challenge study. Each parameter was studied in triplicate at a particular time period. The anesthetized fish (15 fish from each group) were bled by caudal venipuncture on 10th and 30th days post-vaccination. The collected sera samples were stored at $-70{ }^{\circ} \mathrm{C}$ before being used in the study.

Measurement of serum hemolysin and agglutination titers

Serum hemolysin and bacterial agglutinating titers were measured according to Kumari and Sahoo (2005) and Sahoo and Mukherjee (2001). Experimental assays were performed in duplicate for each parameter of the individual fish of all seven groups and the mean \pm SE for each group was calculated. One-way ANOVA followed by DMRT was performed to find out the significant difference $(p \leq 0.05)$ among the groups.

Challenge study

For the challenge study, five fish from each of three replicate tanks of each subgroup (total 15 number of fish) were challenged separately with $\mathrm{LD}_{50}$ dose of $8 \times 10^{5}$ live cells of $A$. hydrophila in $0.1 \mathrm{~mL} \mathrm{PBS} / 20 \mathrm{~g}$ fish via intraperitoneal route (standardized according to Reed and Muench 1938) on 10th and 30th days post-vaccination to study the level of protection induced by different vaccine-adjuvant formulations. The fish were observed for 10 days post-challenge and percent mortality was calculated.

\section{Results}

The SDS-PAGE analysis of different grades of garlic-FKC suspensions incubated for two time intervals showed similar banding patterns. The bands present in the formalin-killed cells only were well preserved in different grades of garlic-FKC suspensions at both time periods of incubations. There was no degradation product noticed in terms of extra fine bands due to effect of garlic extract on FKC samples. Further, two protein bands (one $\sim 14 \mathrm{kDa}$ and another between $\sim 70-90 \mathrm{kDa}$ ), which were present in only garlic sample, were also present in all concentrations of garlic-FKC suspensions (Fig. 1).

The present study demonstrated a significantly high hemolysin titer in the lowest dose of garlic (i.e., $10 \mu \mathrm{g}$ of freeze-dried garlic powder)-adjuvant formulation on day 30. At day 10, all the garlic-injected groups showed increased titers whereas it was the highest in group G. Other groups which received PBS or MO or FKC + MO showed no difference in natural hemolysin titer in comparison to control (Fig. 2).

The effects of different antigenic formulations on days 10 and 30 of injection on specific immunity were measured through bacterial agglutination titer (Fig. 3), which revealed no significant difference in agglutination titer among groups on day 10 . On day 30 , the highest agglutination titer was marked in garlic $(10 \mu \mathrm{g})$ based adjuvant-treated group.

In challenge study, control fish showed highest mortality $(50 \%)$ among the groups challenged 10 days post-vaccination. Group E, which received garlic $(10 \mu \mathrm{g})$-based adjuvant had the lowest mortality $(0 \%)$ among these groups. The groups receiving other two doses of garlic showed similar mortality pattern as compared to the fish in groups received either PBS or MO. (Fig. 4). On day 30, groups E and F, those received garlic $(10$ and $100 \mu \mathrm{g})$-based adjuvant showed the lowest mortality in comparison to all other groups. The highest mortality was recorded in groups B and C which received only PBS or MO. 
Fig. 1 In vitro study on effect of garlic extract on formalinkilled A. hydrophila cells (FKC) by SDS-PAGE. Lane 1 garlic (concentrated), lanes 2, 3, 4 FKC and garlic with three different concentrations 10,100 and 1,000 $\mu \mathrm{g}$, respectively, at $1 \mathrm{~h}$ post-incubation, lanes 5, 6, $7 \mathrm{FKC}$ and garlic $(10,100$ and $1,000 \mu \mathrm{g}$, respectively) at $6 \mathrm{~h}$ postincubation, lane 8 control (only FKC) and lane 9 molecular weight marker
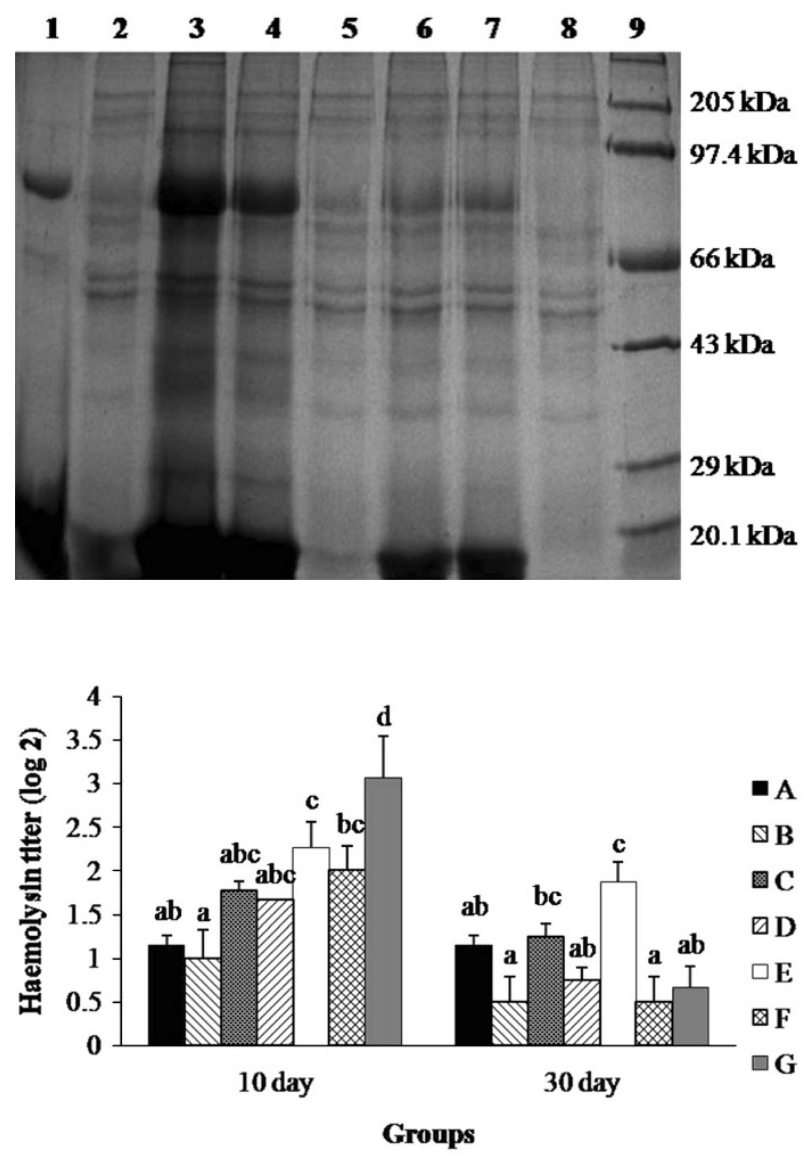

Fig. 2 Variation in serum hemolysin activity. Serum hemolysin activity at days 10 and 30 post-vaccination study. Bars represent mean \pm SE. Mean values bearing same superscripts are not statistically significant, $p \leq 0.05$ on a particular period. Group $A$ control, $B$ injected with PBS, $C$ injected with mineral oil, $D$ injected with FKC + mineral oil, $E, F$ and $G$ injected with $\mathrm{FKC}+$ modified adjuvant with three different concentrations of garlic such as 10,100 and 1,000 $\mu \mathrm{g}$, respectively

Fig. 3 Variation in serum agglutination activity. Agglutination titer at days 10 and 30 post-vaccination study. Bars represent mean \pm SE. Mean values bearing same superscripts are not statistically significant, $p \leq 0.05$ on a particular period. Group $A$ control, $B$ injected with PBS, $C$ injected with mineral oil, $D$ injected with FKC + mineral oil, $E, F$ and $G$ injected with FKC + modified adjuvant with three different concentrations of garlic such as 10,100 and $1,000 \mu \mathrm{g}$, respectively

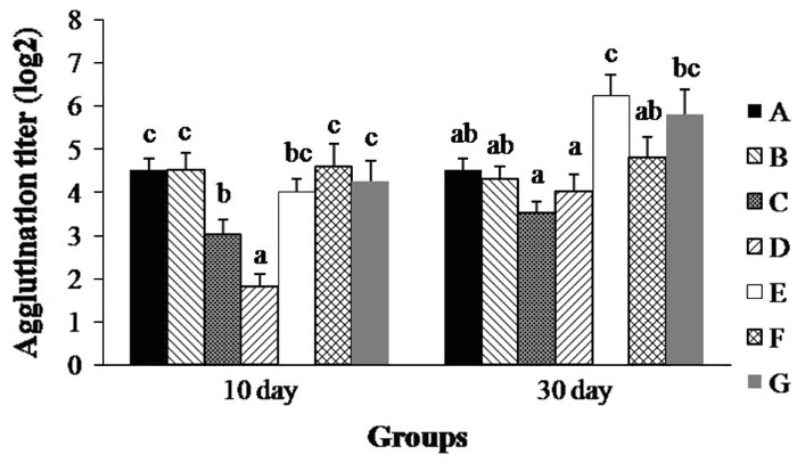

Fig. 4 Variation in \% mortality in different groups at days 10 and 30 challenge study. Group A control, B PBS, $C$ mineral oil, $D$ FKC + mineral oil, $E, F$ and $G$ injected with $\mathrm{FKC}+$ modified adjuvant with three different concentrations of garlic such as 10,100 and $1,000 \mu \mathrm{g}$, respectively. Bars represent mean \pm SE. Mean values bearing same superscripts are not statistically significant, $p \leq 0.05$ at a particular time period

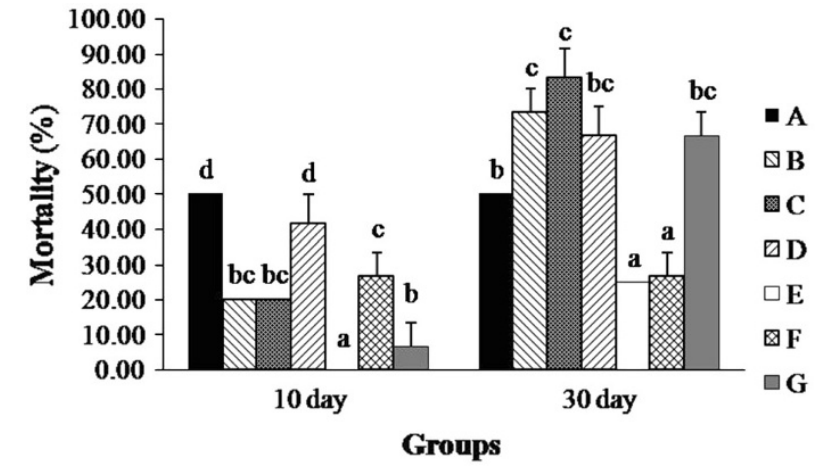




\section{Discussion}

SDS-PAGE analysis of graded garlic sample with FKC is a preliminary study to check the effect of garlic extract on the antigen. The $\sim 14 \mathrm{kDa}$ band evident in only garlic seems to be a glycoprotein which has an array of immunomodulatory functions including stimulation of mononuclear cells, enhancement of NK cell activity, T-lymphocyte proliferation and enhancement of peritoneal macrophage phagocytic activity (Nikoo et al. 2008) whereas the other band has to be characterized. This result indicated that garlic has no proteolytic effect on FKC when used in different concentrations for a varied incubation time and could be used successfully with any antigenic formulations. However, a closer look into its use with new antigen is needed about antigenic degradability before application.

In this study, potential of this modified adjuvant was further evaluated by assessing its immunostimulatory effect on host immunity. Fish serum causes hemolysis of heterologous red blood cells, which is due to activation of alternative pathway of complement system. Garlic might be having some activity which could activate the complement cascade and modulate the innate immune response at early time as well as 30 days post-injection only at lower dose of incorporation. Similarly, previous studies have also found a dosedependent dietary effect of garlic powder in enhancing the immunity of rohu and rainbow trout, besides its positive effects on hematological picture, growth and other serum electrolyte concentrations (Nya and Austin 2009). Lectins are also immune proteins that recognize and bind to specific carbohydrate targets. The lectin pathway of complement system is initiated by binding of a protein complex consisting of mannose-binding lectin (MBL) and serine proteases, mannose-binding lectin associated proteases 1 and 2 (MASP-1 and -2) to mannans on bacterial cell surfaces, and thus its activation is independent of antibody like alternative pathway. Lectin is also regarded as the most abundant protein in garlic (Fenwick and Hanley 1985) and possibly it might be playing role in stimulating the lectin-complement pathway leading to hemolysis of RBCs.

Agglutinins are a group of proteins present in fish serum, which can agglutinate a number of fish bacterial pathogens. These probably have binding affinity for the carbohydrate moieties present on bacterial surface which helps in attachment to the host. The highest agglutination titer in group treated with $10 \mu \mathrm{g}$ of garlicbased adjuvant, showed the garlic-FKC formulation could only able to raise the titer at lowest dose level on day 30. A vaccine formulation of A. hydrophila with propolis induced agglutinating antibody level in carp when injected intraperitoneally (Chu 2006). In fish, antibody-mediated humoral immunity plays an important role in defending bacterial infections. Hence, the antibody titer probably obtained here is well correlated to degree of protection as observed from higher survival in lower dose garlic-treated fish as detailed later. The maximum level of agglutinating antibody 30 days post-vaccination is an indication of the protective response of the modified adjuvant for longer time period which was not seen in only FKC vaccinated group. Detection of highest agglutinating antibody 30 days post-injection is consistent with the results of other workers (Bastardo et al. 2012). In this study, agglutinating antibody titer was also found in control group fish to some extent. Hence the previous exposure of this fish used in this trial to the same or similar antigens/organisms cannot be ruled out in the pond condition where there would be possible exposure to non-pathogenic microbes. Earlier study in our laboratory suggests for the existence of natural agglutinins in Indian major carp sera at any stage of growth (Sahoo et al. 2008).

Herbal extracts are proved to reduce mortality against pathogen challenges (Ardo et al. 2008). Reduction in the mortality in rainbow trout was reported by Nya and Austin (2009) fed with different dose of garlic. Similarly, addition of garlic at $0.1-1 \%$ in the diet of rohu fingerlings for 60 days significantly reduced mortality due to aeromoniasis (Sahu et al. 2007). Garlic could enhance fish immunity even at lower dose when used as dietary supplement (Sahu et al. 2007). In the present study, the lowest mortality rate against $A$. hydrophila challenge was found in the group receiving FKC + MO with garlic in lower dose whereas it was higher in the MO group as well as in the group which received vaccine formulation without garlic. The response of the dose, i.e., $\leq 100 \mu \mathrm{g}$ of garlic might be sufficient enough to stimulate the immune effector molecules against the pathogen. Results of hemolysin titer and challenge study of our experiment showed that the effect of garlic treatment was more pronounced during earlier time period, i.e., $10 \mathrm{dpv}$ as compared to 30 $\mathrm{dpv}$, thus indicating short-lived immunomodulatory effect of the compounds viz., allicin, organo-sulfur compounds or ajoene present in garlic extract. Hence, booster injections with this adjuvant may be more effective to obtain pronounced effect of this compound. 


\section{Conclusion}

Adjuvants play an important role by directing and activating the innate and adaptive immune responses to the poor antigen and develop hope of producing a vaccine with predictable efficacy. Garlic although has a history of medicinal and dietary applications as an anti-infective agent (Reuter et al. 1996), it has never been used as an adjuvant. The result of this study indicated that garlic has immunomodulatory properties and when used with mineral oil, the modified adjuvant formulation is well capable of enhancing protection in L. rohita against A. hydrophila infection. In this experiment, garlic has been found to enhance the serum agglutinating antibody titer as well as hemolysin activity of the serum and also increased the survival rate post-challenge. These findings prove the potential of garlic as an immunoadjuvant as well as its effect on stimulation of specific and nonspecific immune response, particularly when used in lower dose $(\leq 100 \mu \mathrm{g})$. The highly appreciable response in lower dose of garlic might be the contribution of one compound or more than one compounds present in garlic. However, to prove its complete adjuvant potential, further study with long-term trials and on identification of the most active compound of garlic is necessary.

Acknowledgments The authors are thankful to the Director, Central Institute of Freshwater Aquaculture, Kausalyaganga, Bhubaneswar, India for providing necessary facilities during this study.

Author's contribution Pujarini Dash: performing the experiment, data analysis, manuscript drafting. Swati: conducting the experiment, data analysis. P. K. Sahoo: designing of experiment, data analysis, drafting of manuscript.

Open Access This article is distributed under the terms of the Creative Commons Attribution License which permits any use, distribution, and reproduction in any medium, provided the original author(s) and the source are credited.

\section{References}

Angka SL (1990) The pathology of the walking catfish, Clarias batrachus (L.), infected intraperitoneally with Aeromonas hydrophila. Asian Fish Sci 3:343-351

Ardo L, Yin G, Xu P, Varadi L, Szigeti G, Jeney Z, Jeney G (2008) Chinese herbs (Astragalus membranaceus and Lonicera japonica) and boron enhance the non-specific immune response of Nile tilapia (Oreochromis niloticus) and resistance against Aeromonas hydrophila. Aquaculture 275:26-33

Bastardo A, Ravelo C, Castro N, Calheoros J, Romalde JL (2012) Effectiveness of bivalent vaccines against Aeromonas hydrophila and Lactococcus garvieae infections in rainbow trout Oncorhynchus mykiss (Walbaum). Fish Shellfish Immunol 32:756-761

Chandrasekhar PM, Venkatesh YP (2009) Identification of the protein components displaying immunomodulatory activity in aged garlic extract. J Ethnopharmacol 124:384-390

Chillingworth NL, Donaldson LF (2003) Characterization of a Freund's complete adjuvant-induced model of chronic arthritis in mice. J Neurosci Meth 128:45-52

Chu W (2006) Adjuvant effect of propolis on immunisation by inactivated Aeromonas hydrophila in carp (Carassius auratus gibelio). Fish Shellfish Immunol 21:113-117

Corzo-Martinez M, Corzo N, Villamiel M (2007) Biological properties of onions and garlic. Trends Food Sci Tech 18:609-625

Fenwick GR, Hanley AB (1985) The genus Allium. Crit Rev Food Sci Nutr 23:1-73

Kumari J, Sahoo PK (2005) Effects of cyclophosphamide on the immune system and disease resistance of Asian catfish, Clarias batrachus. Fish Shellfish Immunol 19:307-316

Kyo E, Uda N, Suzuki A, Kakimoto M, Ushijima M, Kasuga S, Itakura Y (1998) Immunomodulation and anti tumor activity of aged garlic extract. Phytomedicine 5:259-267

Marsden MJ, Freeman LC, Cox D, Secombes CJ (1996) Non-specific immune responses in families of Atlantic salmon, Salmo salar, exhibiting differential resistance to furunculosis. Aquaculture 146:1-16

Midtlyng PJ, Reitan LJ, Speilberg L (1996) Experimental studies on the efficacy and side-effects of intraperitoneal vaccination of Atlantic salmon (Salmo salar L.) against furunculosis. Fish Shellfish Immunol 6:335-350

Mu X, Pridgeon JW, Klesius PH (2011) Transcriptional profiles of multiple genes in the anterior kidney of channel catfish vaccinated with an attenuated Aeromonas hydrophila. Fish Shellfish Immunol 31:1162-1172

Nikoo S, Bozorgmehr M, Ahamadabad HN, Hassan ZM, Moazzeni SM, Pourpak Z, Ghazanfari T (2008) The 14 kDa protein molecule isolated from garlic suppresses indoleamine 2, 3-dioxygenase metabolites in mononuclear cells in vitro. Iran $\mathrm{J}$ Allergy Asthma Immunol 7:203-208

Nya EJ, Austin B (2009) Use of garlic (Allium sativum) to control Aeromonas hydrophila infections in rainbow trout Oncorhynchus mykiss (Walbum). J Fish Dis 32:963-970

Poppe TT, Breck O (1997) Pathology of Atlantic salmon Salmo salar intraperitoneally immunized with oil-adjuvanted vaccine. A case report. Dis Aquat Org 29:219-226

Reed LJ, Muench H (1938) A simple method of estimating fifty percent end points. Am J Hyg 27:493-497 
Reuter HD, Koch HP, Lawson LD (1996) Therapeutic effects and applications of garlic and its preparations. In: Koch HP, Lawson LD (eds) Garlic, the science and therapeutic application of Allium sativum L. and related species. Williams and Wilkins, Baltimore, pp 135-212

Roed KH, Brun E, Larsen HJ, Refstie T et al (1992) Genetic variation in serum haemolytic activity in Atlantic salmon (Salmo salar L.). J Fish Biol 0:739-750

Sahoo PK, Mukherjee SC (2001) Effect of dietary $\beta-1,3$ glucan on immune responses and disease resistance of healthy and aflatoxin B1 induced immunocompromised rohu (Labeo rohita Hamilton). Fish Shellfish Immunol 11:683-695

Sahoo PK, Mahapatra KD, Saha JN, Barat A, Sahoo M, Mohanty BR, Gjerde B, Ødegård J, Rye M, Salte R (2008) Family association between immune parameters and resistance to Aeromonas hydrophila infection in the Indian major carp, Labeo rohita. Fish Shellfish Immunol 25:163-169

Sahu S, Das BK, Mishra BK, Pradhan J, Sarangi N (2007) Effects of Allium sativum on the immunity and survival of Labeo rohita infected with Aeromonas hydrophila. J Appl Icthyol 23:80-86

Salamatdoust R, Kiyani M (2012) Use of SDS-PAGE to measure protein degradation of treated soybean with Pinus eldarica extract. Global Vet 9:175-178

Yin G, Ardo L, Thompson KD, Adams A, Jeney Z, Jeney G (2009) Chinese herbs (Astragalus radix and Ganoderma lucidum) enhance immune response of carp, Cyprinus carpio, and protection against Aeromonas hydrophila. Fish Shellfish Immunol $26: 140-145$ 